\title{
The Conditional Relationship between Inequality and Development
}

Carles Boix, Princeton University

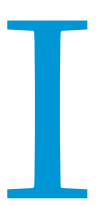

$\mathrm{n}$ recent years political scientists and economists have spent considerable efforts investigating the impact of income inequality both on political institutions and social conflict (Boix 2003, 2008; Acemoglu and Robinson 2006; Geddes 2007) and on growth and development (Atkinson and Bourguignon 200o). In this article I focus on the latter question: I discuss the extent to which (that is, the conditions under which) inequality may hinder economic growth. I do so by moving away from the current literature, which models the relationship between development and inequality in a linear fashion-with the latter unconditionally distorting (or boosting) the incentives to invest and therefore reducing (or increasing) the rate of growth. Instead, I claim that the potential correlation between inequality and development will be always conditional on the (mostly political and institutional) causes that generate the existing income distribution to start with. Hence it is not surprising to find instances in which growth and (mostly temporary) inequality come hand in hand as well as other periods and countries where there is both high and persistent inequality jointly with economic stagnation.

The article is organized as follows. The first section reviews the existing theoretical literature on the economic consequences of inequality. The second section summarizes the (mostly inconclusive) empirical literature on the problem at hand. The final section offers an alternative explanation that stresses the contingent relationship between inequality and development across time. That explanation accounts both for the joint outcome of low growth and high inequality that characterizes many underdeveloped economies and for those temporary spells of high growth and increasing income heterogeneity experienced by developed economies from time to time (such as nineteenth-century Europe or in several Organisation for Economic Co-operation and Development [OECD] economies in the last decades).

\section{SHIFTING THEORIES OF INEQUALITY AND GROWTH}

Research about the relationship between economic development and income distribution has evolved over different phases in the last decades. Initially, inequality was mostly taken to be correlated with but causally irrelevant to economic growth. Lewis (1954) predicted that in modernizing economies inequality would increase, at least in the short run, as labor started to move from the low-income traditional sector to the highincome sectors. More famously perhaps, Kuznets (1955) saw the process of development as triggering a population shift (away from rural and non-agricultural sectors) that, under certain assumptions, would lead to a temporary rise in overall inequality. In fact, although his famous conjecture about the (curvilinear) relationship between inequality and development spurred an extraordinary amount of empirical research (with rather inconclusive results), Kuznets never intended to assert that inequality was a necessary condition of economic takeoff. Still, a few articles such as Galenson and Leibenstein (1955) claimed that inequality was a prerequisite of economic takeoffs. Assuming that the propensity to save grew with income, they predicted that more skewed income distributions should generate higher investment rates and therefore higher growth rates.

By the late 1980 os and early 1990s, however, both economic theorists and economic historians were casting inequality as a roadblock in the way of prosperity-through, at least, three different mechanisms. First, several articles insisted that, by exacerbating redistributive demands, inequality resulted in a heavier tax burden, the introduction of distortions to productive incentives, and, therefore, the slowdown of growth (Bertola 1993; Perotti 1993; Alesina and Rodrik 1994; Persson and Tabellini 1994). A second set of articles linked inequality to political instability (in the form of more riots, assassinations, and civil wars) and therefore to a legal framework hardly conducive to the protection of property rights and to economic investment (Venieris and Gupta 1986; Alesina and Perotti 1996). Finally, inequality led to underdevelopment through strictly financial channels: if, due to imperfect capital markets, poor individuals have no access to collateral to borrow and escape poverty, in a highly unequal society a higher number of individuals would be affected by a poverty trap and growth would be lower than in more equal societies.

\section{INCONCLUSIVE EMPIRICAL EVIDENCE}

In the first systematic studies of the impact of inequality on development, generally based on ordinary least squares estimations of cross sections of countries covering a time period of a few decades (normally from 1960 to the 1980s), inequality was consistently found to reduce growth-with an increase in inequality by one standard deviation decreasing the annual growth rate of per capita income by 0.4 to 0.8 percentage points (Alesina and Rodrik 1994; Persson and Tabellini 1994; Alesina and Perotti 1996; Perotti 1996; Deininger and Squire 1998). That quantity was between one-third and two-fifths of the standard deviation of growth rates in most samples. Moreover, the negative effect of land inequality on growth turned out to be more robust than income inequality, that is, it remained statistically significant after the introduction of regional dummies for Latin America, Africa, and Asia (Deininger and Squire 1998).

After correcting for omitted-variable bias (such as institutional and legal setups, national cultural traits, and so on) 
employing a country and period fixed-effects model, Li and Zou (1998) and Forbes (2000) found that higher levels of inequality increase growth. According to Li and Zou, increasing the Gini coefficient by one standard deviation raises the annual growth rate by almost half a percentage point. In Forbes the growth rate increases by 1.3 percentage points.

In turn Barro (2000) employed a three-stage least-square estimator with random country effects. The effect of initial inequality on growth was not significant from a statistical point of view. Still, after dividing the sample between rich and poor countries, Barro found that the coefficient of inequality was statistically significant: in the negative direction among poor countries and positively for rich countries.

In line with the theoretical literature reviewed in the first section, all those studies assumed that inequality and growth are related linearly-although Barro's split sample may be interpreted as an exception to that general approach. More recent studies have moved to estimate, instead, a model in which inequality and the growth rate are related through a concave schedule. In Banerjee and Duflo (2003) an increase in inequality reduces growth but a decrease does too. Voitchovsky (2005) estimates the separate effect of the inequality of incomes at the top and the bottom of the income distribution on growth. Higher levels of inequality at the top of the distribution are positively correlated with growth. By contrast, higher inequality in the bottom half of the distribution results in less growth.

To sum up, the existing empirical work on the relationship between inequality and development is inconclusive. That may be due to strict methodological problems in the estimations: the quality of the data is low and the span of time usually employed is too short to derive meaningful conclusions (particularly because it does not include the period of the industrial takeoff). But, as I would like to develop in the next section, it may be simply due to the fact that the true relationship between growth and inequality varies over time and across space and that what researchers have done so far has been capturing different, partial realizations of that relationship.

\section{A CONDITIONAL RELATIONSHIP? ${ }^{1}$}

\section{Initial Set-Up}

To think about the ways in which inequality may be conditionally related to development (either negatively or positively), let us start with a simple model, which the standard literature employs to represent individual income (in current models of intergenerational transmission of inequality):

$$
k_{i, t+1}=f\left(k_{i, t}\right)-c_{i, t}+\varepsilon_{t}
$$

where $k$ represents the assets of individual $i, c$ is the fraction individual $i$ consumes at period $t$ and $\varepsilon$ is some idiosyncratic shock that may affect the assets at time $t$.

The most general (and plausible) interpretation of this functional form is a world where there is intergenerational transmission of wealth among families or individuals. Individuals have some initial wealth $k$ (for example, inherited from parents) that they allocate to maximize their expected wealth at the end of the period. After consuming some of their wealth, they bequeath the rest to their children. ${ }^{2}$
Assume that, following Solow's aggregate neoclassical growth model, the world is one in which each individual invests $k$ and where there is a common production function $f(k)$ that is strictly increasing and concave. Assume also that, at the very beginning, and as a result of a random shock, individuals are differently endowed in $k$, that is, that there is some initial inequality in the distribution of assets (and income). With no credit markets in place, the expected marginal return on investment is higher for poor individuals. Hence, the average wealth of poor individuals (or families) will grow faster than the average wealth of rich families. Provided there are no shocks of the type embodied by $\varepsilon$, the wealth of every family will converge to a steady state with wealth $k^{*}$. Under this very simple scenario, we will observe the two following facts at the aggregate level and over time: the average growth rate will be positive (as all individuals accumulate capital until reaching $k^{*}$ ) and inequality will decline (and effectively disappear once they all reach $k^{*}$ ). In fact, the highest growth rates will coincide with the fastest declines in income inequality. Overall, inequality and growth will be negatively related.

\section{Technological Shocks and the Kuznets Curve}

Consider next the possibility that at some point a fraction $h$ of all individuals adopts a more efficient technology of production $f_{h}(k)$ such that $f_{h}()>.f($.). This will generate a higher average income in the economy-both because the production function shifts upward for the $h$ individuals at $k^{*}$ and because they start moving toward a new steady-state $k_{h}^{*}$. This process of growth will be also correlated with a widening income distribution. Provided that the access to the new technology of production is not restricted in any permanent way, the remaining fraction of individuals $(1-h)$ will adopt it in due time (with, say, some temporal lag). Accordingly, all incomes will converge again. Equality will be back into place after some time.

From a dynamic point of view, we will observe a first period of both a growing average income (due to increased incomes among $h$ individuals) and increasing inequality. That will be then followed by a second (and final) period with additional growth in per capita income (generated by the growth of the non- $h$ individuals) and declining inequality. The insights of Kuznets's path-breaking paper on economic growth and income inequality (Kuznets 1955) seem to fit this pattern. According to Kuznets, the process of economic development triggers a population shift from rural to nonagricultural sectors. Given certain assumptions about the mean and variance of income in each sector, growth leads to a rise in overall inequality. This increase should be temporary, however, as populations continue to shift to the industrial sector and the majority of individuals draw their incomes from that latter sector. ${ }^{3}$

Notice that the key factor in this story (and one that is generally forgotten in all the existing economic models on inequality and growth) is whether the non- $h$ individuals will be able (in fact, allowed) to adopt the new technology $f_{h}($.$) or$ not. If there are some barriers to entry, that is, if adopting the new technology has some costs that prevent some individuals from becoming more efficient, the process of income equalization (and, as a matter of fact, the last part of income growth) 
will not occur. Those barriers to entry may take several forms. They may consist in a direct prohibition (imposed by $h$ individuals) to adopt the new technology to make sure the $h$ sector enjoys higher (monopolistic) returns. They may derive from having thin credit markets that prevent low-income individuals to borrow to make the type of expenditure needed to adopt $f_{h}($.$) .$

\section{Barriers to Entry, Complementarities, and Political Institutions}

Under what conditions will these barriers be present (or absent) and thus will inequality remain in place (or disappear)? For the sake of simplicity, let us assume that access to policy (in the sense of having a decisive influence over decisions) is directly related to income so that only high-income individuals (the $h$ individuals after the new technological lated with being the first to adopt better technologies of production in previous periods).

The absence of convergence to a unique steady-state $k_{h}^{*}$ does not only happen when the $h$ sector explicitly imposes some legal barriers to the adoption of the new technology. "Natural" barriers may also create permanent inequalities among individuals. To see why, assume that the new technology $f_{h}$ only gives a higher return than $f($.) if $\underline{k}>k$. If credit markets are not developed enough, poor individuals at the time of the technological shock (those with $k<\underline{k}$ ) will not be able to catch up with the $h$ individuals. A solution to the problem would be to reform credit markets. A second solution may consist in transferring some fraction of $k$ (in the form of money, skills, etc.) to the poor. If there are economic complementarities between $h$ and non- $h$, that is, if the sector with the better technology gains from having more people

\section{Thus, for example, in a democratic setting, which is always characterized by a strong equalizing bias, voters may be tempted to block growth-enhancing technological shocks that may reduce their income or that simply increase inequality. Moving closer to one of the main empirical facts that motivate this article, the persistence of inequality and economic stagnation in developing economies derives from the fact that their political and economic elites have very little incentives to transform their countries into open economies.}

shock) determine whether barriers to entry should be introduced or not. For example, individuals $h$ impose their preferred solution by funding political campaigns in democracies. More extremely, they spend some of their resources to explicitly exclude the rest of the population from the decisionmaking process.

If the $h$ entrepreneurs only care about absolute income, they will not have any incentive to block access to the new technology provided-although it leads to the gradual equalization of incomes, the spread of $f_{h}($.) to everyone does not affect their income. This scenario matches the cyclical behavior of a typical open economy: in such an economy there are outbursts of technological change that generate faster growth rates and a broadening income gap; over time, however, individuals catch up and the economy moves back to some equality of income. (Because technological change never stops in modern economies, complete equalization never happens.)

Still, this rosy scenario of sudden growth followed by re-equilibration may not always happen. The members of the $h$ sector will have an incentive to block or slow down the extension of new technologies of production to the remaining economic agents if they care about relative incomes, if they can capture some rents from creating non-perfectly competitive markets, if they care about governing (and their chances of governing are boosted by having more resources), and/or if having an initial technological advantage helps them to sustain some technological advantage over time (that is, if the likelihood of adopting a more efficient $f($.) is positively corre- adopting or knowing it, the $h$ sector (which, so far, controls policy) will have strong incentives to devise mechanisms to overcome those natural barriers. In that instance, we should see again some equalization of conditions in place. In fact, this is the tale that Lindert (2004) and Galor and Moav (2006) tell about the process of industrialization in parts of Europe. The technological shocks of the nineteenth century led to growing inequalities first and then to the support of industrialists for publicly financed education schemes to improve their workforce and, as a result, their own profits.

Given this general story about technological shocks and the potential emergence of legal or natural barriers, political institutions must play an important role to explain the behavior of growth and equality. As I have already pointed out, inequality will tend to persist over time if only the $h$ individuals control the policymaking process-and there are no complementarities that may convince them to invest in those poor individuals with assets $k<\underline{k}$. Logically, under a different political regime, one where non- $h$ individuals decide, there will be strong incentives to block legal barriers or to establish mechanisms to reduce any natural barriers. In other words, if non- $h$ individuals are the majority of the population, then democracy should generate more equality in the long run. (Still, democracy is neither a sufficient nor a necessary condition of growth and equalization. It is not a sufficient condition because even if there is democracy, the process of investment in poor individuals [those with $k<\underline{k}$ ] will not happen if the majority 


\section{Figure 1}

\section{Correlation between Absence of Corruption and Level of Inequality}

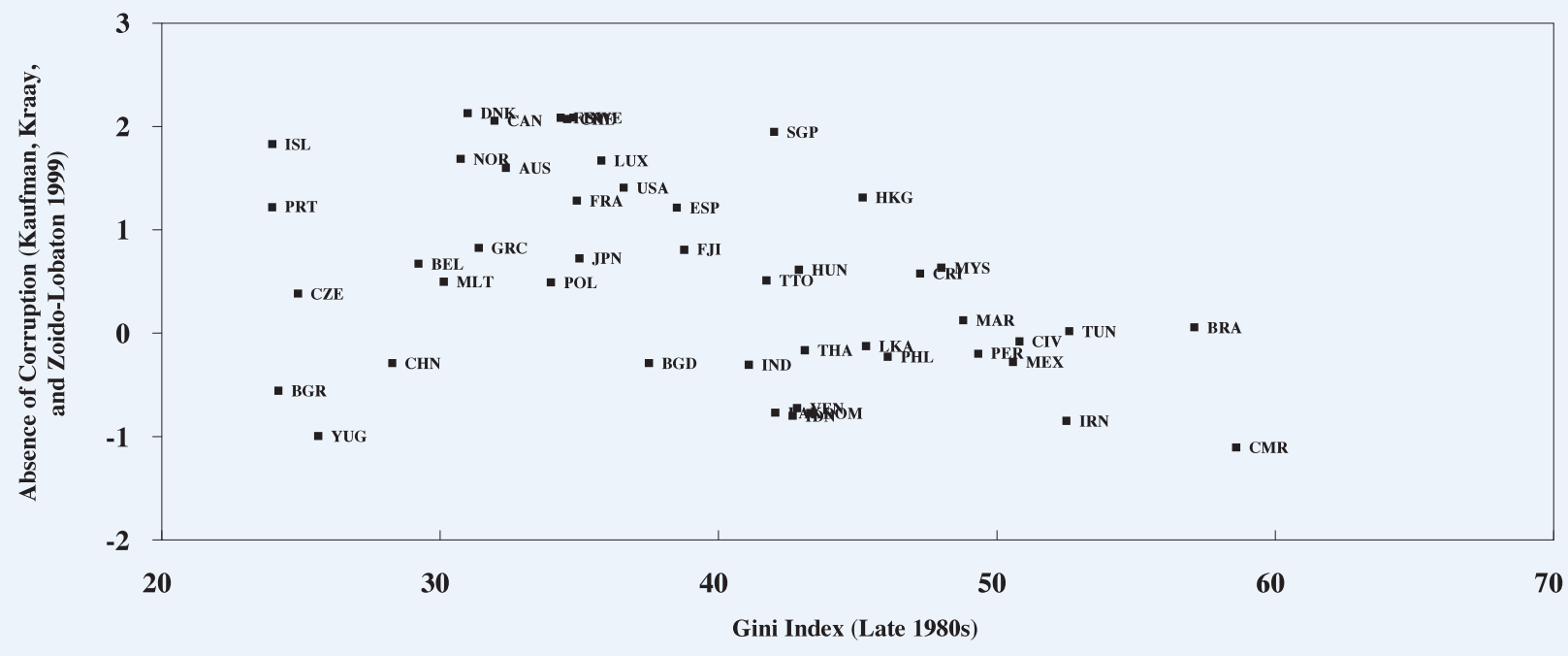

of the population belongs to the $h$ sector. It is not a necessary condition either because, as I discussed above, income convergence can happen provided the sector $h$ only cares about absolute incomes or wants to exploit some complementarities across sectors.)

\section{Politically Endogenous Barriers}

So far we have only considered the case in which there is an exogenous technological shock and where economic agents react ex post by choosing a particular regulatory framework. However, in most instances, technological shocks (and their adoption among economic agents) do not happen randomly. Instead, precisely because they affect the income of individuals, they are endogenous to certain political configuration. Hence, as I discussed more formally in Boix (2009b), those sectors that control policymaking (i.e., the "decisive" voters) have a strong interest in controlling or regulating the access to the technologies of production. To put it differently, the introduction of a regulatory framework that could spur technological advances and growth will be a function of the incentives of policymakers.

Thus, for example, in a democratic setting, which is always characterized by a strong equalizing bias, voters may be tempted to block growth-enhancing technological shocks that may reduce their income or that simply increase inequality. ${ }^{4}$ Moving closer to one of the main empirical facts that motivate this article, the persistence of inequality and economic stagnation in developing economies derives from the fact that their political and economic elites have very little incentives to transform their countries into open economies.

Before industrialization, wealth and income was heavily distributed on the basis of political access to power (which was, in turn, well related to military skills [Boix 2009a]). Wealth was therefore based on the ownership of very specific assets-assets whose value hinged on regulatory barriers sustained by the state and/or wealth (such as land) that could not be easily redeployed in new, more productive economic sectors. Because wealth was so specific to the sector in which it was deployed, the wealthy strata and the governing elite (both of which overlapped to a great extent) had very little interest in changing the status quo and in accepting any technological breakthrough that could upset their dominant economic and political position. Under that political and economic context, inequality and long-run economic stagnation (underpinned by a non-democratic regime) ended up taking place simultaneously.

The same joint pattern both of differential access to the state and to regulation (and wealth) and of economic stagnation prevails in the underdeveloped world today. Although there are no good measures of differential access to economic and political power, the level of corruption may be interpreted as a proxy for all the mechanisms employed to secure personal favors and to avoid the transparency and equality nominally embodied in the legal system. Figure 1 shows the existing correlation between the level of inequality (measured through the Gini index) and the absence of corruption for a cross section of countries. Unsurprisingly, both measures are well correlated. Higher levels of corruption come jointly with more inequality.

\section{CONCLUSION}

In contrast to the existing literature on growth and inequality, which models them as linearly related, I have suggested that the behavior of both factors is conditional on the set of political and social institutions in which they are embedded. In open economies, where technological shocks happen with some regularity and affect different individuals with some temporal lags, it is not unusual to see growth and a widening income distribution, generally followed by a period of income convergence. By contrast, in closed economies, which define Ancien Régime societies, their elites employ a heavy dose of regulation to sustain their economic advantage over the rest 
of society-even if it is at the cost of blocking economic innovation and growth.

\section{NOTES}

1. This section is based on Boix (2009a, 2009b).

2. Unsurprisingly, the main point of contention among researchers working with this class of models has to do with the particular functional form that expression (1) takes - and, particularly, with the behavior of the function $f($.) and the parameter $\varepsilon$. I do not deal with this question here. For comprehensive reviews of the literature, see Atkinson and Bourguignon (2000) and Kahhat (2008).

3. For some confirmation of the Kuznets's conjecture in Britain, see Lindert (2000). For some partial confirmation in a cross section of countries, see Barro (2008).

4. Voters block change especially if they are not compensated through higher transfers (Rodrik 1998; Adserà and Boix 2002).

\section{RE F E R E N C E S}

Acemoglu, Daron, and James A. Robinson. 2006. Economic Origins of Dictatorship and Democracy. New York: Cambridge University Press.

Adserà, Alicia, and Carles Boix. 2002. "Trade, Democracy and the Size of the Public Sector: The Political Underpinnings of Openness." International Organization 56 (2): 229-62.

Alesina, Alberto, and Roberto Perotti. 1996. "Income Distribution, Political Instability and Investment." European Economic Review 40 (6): 1203-28.

Alesina, Alberto, and Dani Rodrik. 1994. "Distributive Politics and Economic Growth." Quarterly Journal of Economics 109 (2): 465-90.

Atkinson, A.B., and F. Bourguignon. 20oo. "Introduction: Income Distribution and Economics." In Handbook of Income Distribution, ed. A. B. Atkinson and F. Bourguignon. Amsterdam: Elsevier Science, 1-58.

Banerjee, Abhijit V., and Esther Duflo. 2003. "Inequality and Growth: What Can the Data Say?" Journal of Economic Growth 8 (3): 267-99.

Barro, Robert. 200o. "Inequality and Growth in a Panel of Countries." Journal of Economic Growth 5 (1): 5-32.

. 2008. "Inequality and Growth Revisited.” Working Paper Series on Regional Economic Integration no. 11, Asian Development Bank.

Bertola, Giuseppe. 1993. "Factor Shares and Savings in Endogenous Growth." American Economic Review 83 (5): 1184-99.

Boix, Carles. 2003. Democracy and Redistribution. New York: Cambridge University Press.

. 2008. "Economic Roots of Civil Wars and Revolutions in the Contemporary World." World Politics 60 (April): 390-437.

- 2009a. "A Theory of State Formation and the Origins of Inequality." Princeton University. Unpublished manuscript. 2009b. "Economic Inequality under Political Institutions." Princeton University. Unpublished manuscript.

Deininger, Klaus, and Lyn Squire. 1998. "New Ways of Looking at Old Issues: Inequality and Growth." Journal of Development Economics 57 (2): 259-87.

Forbes, Kristin J. 200o. "A Reassessment of the Relationship between Inequality and Growth." American Economic Review 90 (4): 869-87.

Galenson, Walter, and Harvey Leibenstein. 1955. "Investment Criteria, Productivity and Economic Development." Quarterly Journal of Economics 69: 43-70.

Galor, Oded, and Omer Moav. 2006. "Das Human Capital: A Theory of the Demise of the Class Structure." Review of Economic Studies 73 (1): 85-117.

Geddes, Barbara. 2007. "What Causes Democratization?" In The Oxford Handbook of Comparative Politics, ed. Carles Boix and Susan Stokes. New York: Oxford University Press, chapter 14.

Kahhat, Jaime. 2008. "Markets and the Dynamics of Inequality." Background paper prepared for the project "Markets, the State and the Dynamics of Inequality: How to Advance Inclusive Growth." UNDV, Bureau of Development Policy, Poverty Group.

Kaufman, D., A. Kraay, and P. Zoido-Lobaton. 1999. "Aggregating Governance Indicators.” Working paper no. 2195, The World Bank, Washington, D.C.

Kuznets, Simon. 1955. "Economic Growth and Income Inequality." American Economic Review 45 (March): 1-28.

Lewis, W.A. 1954. "Economic Development with Unlimited Supplies of Labor." Manchester School of Economics and Social Studies 22: 39-81.

Li, Hongyi, and Heng-fu Zou. 1998. "Income Inequality Is Not Harmful for Growth: Theory and Evidence." Review of Development Economics 2 (3): 318-34.

Lindert, Peter. 200o. "Three Centuries of Inequality in Britain and America." In Handbook of Income Distribution, ed. A. B. Atkinson and F. Bourguignon. Amsterdam: Elsevier Science, 167-216.

-2004. Growing Public. Social Spending and Economic Growth Since the Eighteenth Century. New York: Cambridge University Press.

Perotti, Roberto. 1993. "Political Equilibrium, Income Distribution, and Growth.” Review of Economic Studies 6o (4): 755-76.

-1996. "Growth, Income Distribution, and Democracy: What the Data Say." Journal of Economic Growth 1 (2): 149-87.

Persson, Torsten, and Guido Tabellini. 1994. "Is Inequality Harmful for Growth?" American Economic Review 84 (3): 60o-21.

Rodrik, Dani. 1998. "Why Do Open Economies Have Bigger Governments?" Journal of Political Economy 106: 97-1032.

Venieris, Yiannis P., and Dipak K Gupta. 1986. "Income Distribution and Sociopolitical Instability as Determinants of Savings: A Cross-Sectional Model." Journal of Political Economy 94 (4): 873-83.

Voitchovsky, Sarah. 2005. "Does the Profile of Income Inequality Matter for Economic Growth? Distinguishing Between the Effects of Inequality in Different Parts of the Income Distribution." Journal of Economic Growth 10 (3): $273-96$ 